\title{
Choroid plexus carcinoma in an adolescent male: a case report
}

\author{
Patel Zeeshan Jameel ${ }^{*}$ (1) Ashish Varma, Pooja Kumari, Keta Vagha, Jayant Vagha and Sachin Damke
}

\begin{abstract}
Introduction/background: Although central nervous system tumors are the most common etiology of malignancies in the pediatric age group, choroid plexus carcinomas are rare, with an annual incidence rate of 0.10 per 100,000 children.

Case presentation: We report the case of an adolescent male belonging to central India who had presented with a history of persistent headache, projectile vomiting, neck stiffness, and an episode of generalized tonic-clonic seizure. Neurological examination was suggestive of a space-occupying lesion. Further neuroimaging was suggestive of a large left-sided choroid plexus carcinoma, later confirmed on pathological examination. Gross total resection was achieved and followed by radiation therapy. His recovery was satisfactory without any major events despite suffering from such a malignancy with a poor prognosis.

Conclusion: In the absence of a global consensus on choroid plexus carcinoma management, our patient underwent a successful gross total resection and received postoperative radiotherapy. He made a satisfactory recovery with a further plan to review with gadolinium-enhanced neuroimaging at a later date. We conclude that, when possible, achieving gross total resection is of utmost importance.
\end{abstract}

Keywords: Choroid plexus carcinoma, Brain tumor, Gross total resection

\section{Introduction}

Central nervous system (CNS) tumors are the most common etiology of cancer in the pediatric age group (0-19 years) with an incidence rate of 5.57 per 100,000 population [1]. Among them, choroid plexus tumors (CPTs) have an average annual age-adjusted incidence rate of 0.10 per 100,000 children, being most common in the age group $0-4$ years [1]. Overall, CNS tumors may have grave consequences, with a mortality rate of 0.65 per 100,000 children.1 As per the World Health Organization (WHO) classification, CPTs are further subclassified into choroid plexus papilloma (CPP; WHO grade I), atypical choroid plexus papilloma (WHO grade II), and choroid plexus carcinoma (CPC; WHO grade III) [2].
$\mathrm{CPC}$ is an exceptionally rare intracranial neoplasm characterized histologically by friable papillary or cauliflower-like appearance, increased mitotic figures, pleomorphic nuclei, and necrosis [3]. CPC was found to be more common among males and significantly associated with younger age (median age 1 year) at diagnosis in comparison with CPP [4]. The clinical presentation is determined by the age of onset, as well as location and size of the tumor. Current management strategies, although not standardized, include gross total resection of the tumor followed by chemotherapy and radiation therapy (RT).

Here, we describe a rare case of pediatric $\mathrm{CPC}$ in the lateral ventricle of an adolescent male and briefly review the current management strategies.

*Correspondence: zeeshan1311@gmail.com

Department of Paediatrics, Jawaharlal Nehru Medical College, Sawangi

(Meghe), Wardha, Maharashtra 442001, India

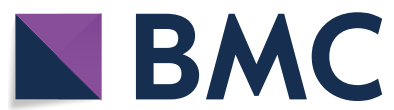

2021. Open Access This article is licensed under a Creative Commons Attribution 4.0 International License, which permits use, sharing, adaptation, distribution and reproduction in any medium or format, as long as you give appropriate credit to the original author(s) and the source, provide a link to the Creative Commons licence, and indicate if changes were made. The images or other third party material in this article are included in the article's Creative Commons licence, unless indicated otherwise in a credit line to the material. If material is not included in the article's Creative Commons licence and your intended use is not permitted by statutory regulation or exceeds the permitted use, you will need to obtain permission directly from the copyright holder. To view a copy of this licence, visit http://creativecommons.org/licenses/by/4.0/. The Creative Commons Public Domain Dedication waiver (http://creativeco mmons.org/publicdomain/zero/1.0/) applies to the data made available in this article, unless otherwise stated in a credit line to the data. 


\section{Case presentation}

A 14-year-old adolescent male belonging to central India presented to our tertiary care health facility in central India with a history of persistent headache for 2 weeks, projectile vomiting for 5 days, neck stiffness for 5 days, and a single episode of generalized tonic-clonic seizure (GTCS) lasting for 10 minutes. Papilledema was present. Systemic examination showed right-sided hemiparesis (power 2/5) with exaggerated deep tendon reflexes and a positive Babinski sign suggestive of an intracranial spaceoccupying lesion (SOL).

After initial stabilization, brain magnetic resonance imaging (MRI) revealed a heterogeneously enhancing mass $(6.2 \times 5.2 \times 4 \mathrm{~cm})$, located in the left lateral ventricle extending diffusely into the ipsilateral parietooccipital region with perilesional edema with a midline shift of $6 \mathrm{~mm}$ (Fig. 1). There were no signs of spinal cord involvement. Magnetic resonance (MR) spectroscopy showed reduced $N$-acetyl-aspartate (NAA) and increased choline, with a lactate peak suggestive of a malignant mass.

Gross total excision of the tumor was achieved with coagulation of the choroid plexus. Intraoperative findings revealed a soft, cystic, necrotic, and highly vascular tumor with intraventricular extension. Histopathological examination revealed crowded and branched papillae merging to form sheets of tumor cells disrupted by areas of necrosis with tumor cells exhibiting nuclear pleomorphism (multilobulated, multinucleated hyperchromatic nuclei). Mitoses were readily identified (15-20/10 hpf). Surrounding brain parenchyma infiltration was also noted (Fig. 2). Immunohistochemistry showed tumor cells expressing cytokeratin (focal) and P53 (diffuse) but did not express synaptophysin, glial fibrillary acidic protein (GFAP), or epithelial membrane antigen (EMA). Also, MIB-1 nuclear labeling was increased markedly, with the index being approximately $40 \%$ in areas of

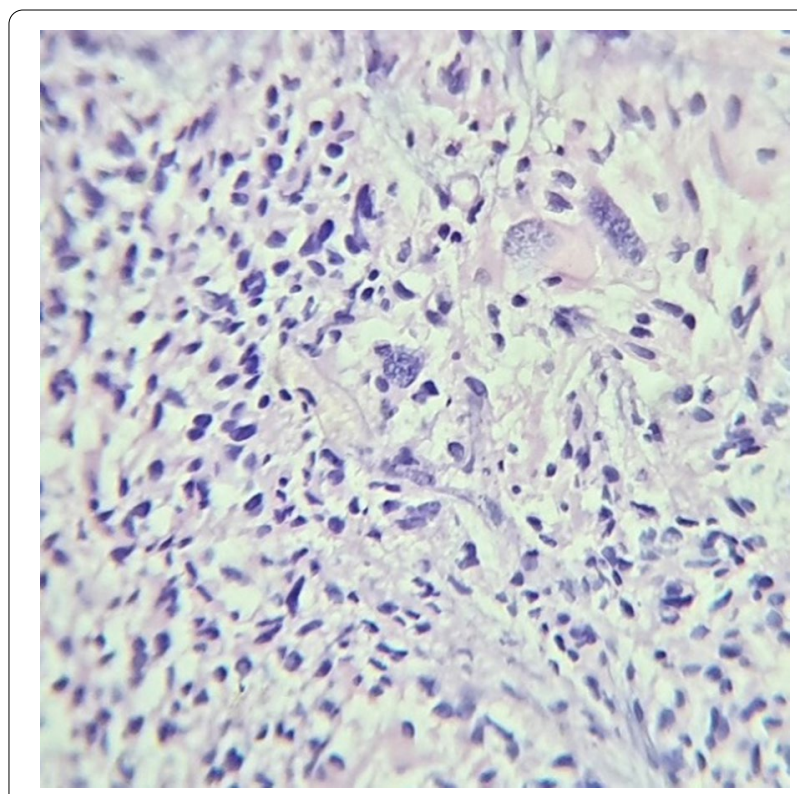

Fig. 2 Histological examination showing crowded and branched papillae merging to form sheets of tumor cells disrupted by areas of necrosis with tumor cells exhibiting nuclear pleomorphism with readily identifiable mitoses
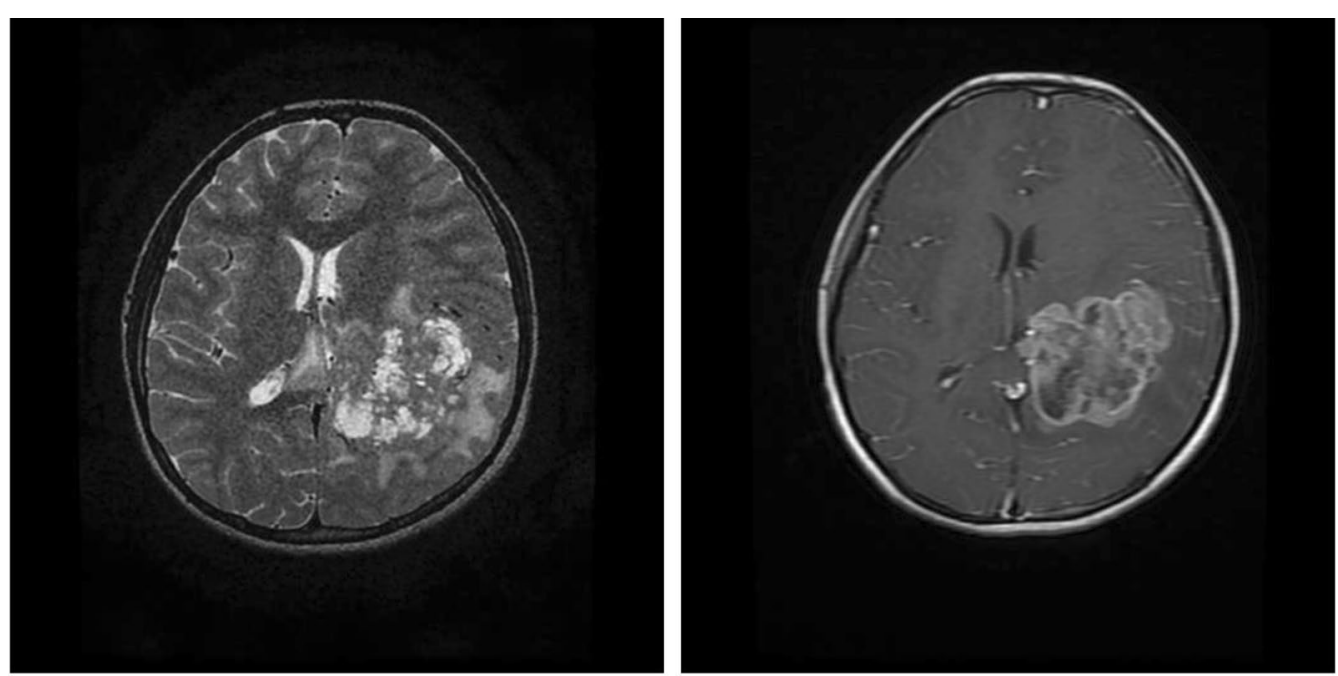

Fig. 1 a T2 weighted image (T2WI) showing heterogeneous space occupying lesion (SOL) with necrotic areas with epicenter in left trigone of lateral ventricle infiltrating into adjacent white matter with surrounding vasogenic edema. (b) Postcontrast T1WI showing heterogeneous enhancement with multiple nonenhancing necrotic areas 
highest proliferative activity. Hence, a diagnosis of choroid plexus carcinoma (CPC) was rendered.

The patient's postoperative recovery was satisfactory with improved power (5/5 on the right side) and resolution of all symptoms. The patient was planned for adjuvant radiotherapy. He received 59 Gy of cranial radiation in 33 fractions using intensity-modulated radiation therapy (IMRT). Follow-up imaging after 3 months showed no residual neoplastic lesion with no metastatic lesion elsewhere on CNS imaging (Fig. 3). The further management plan includes close follow-up for the next 6 months with neuroimaging again 1 year postsurgery.

\section{Discussion}

Choroid plexus carcinoma $(\mathrm{CPC})$ is a rare cause of a hemispheric cerebral tumor arising from lateral ventricles in children. The possible differential diagnosis for such a hemispheric brain tumor includes choroid plexus papilloma (CPP), ependymoma, atypical teratoid rhabdoid tumor, glioma, astrocytoma, and primitive neuroectodermal tumor (PNET). Radiopathological correlation with tissue immunohistochemistry is of essence in differentiating and establishing a confirmatory diagnosis.

The extremely low incidence of CPC in children has been a major obstacle in the development of standardized clinical trials with the therapeutic options being based upon expert opinion and case studies. Various management strategies include surgery, chemotherapy, radiotherapy, and autologous hematopoietic cell rescue.

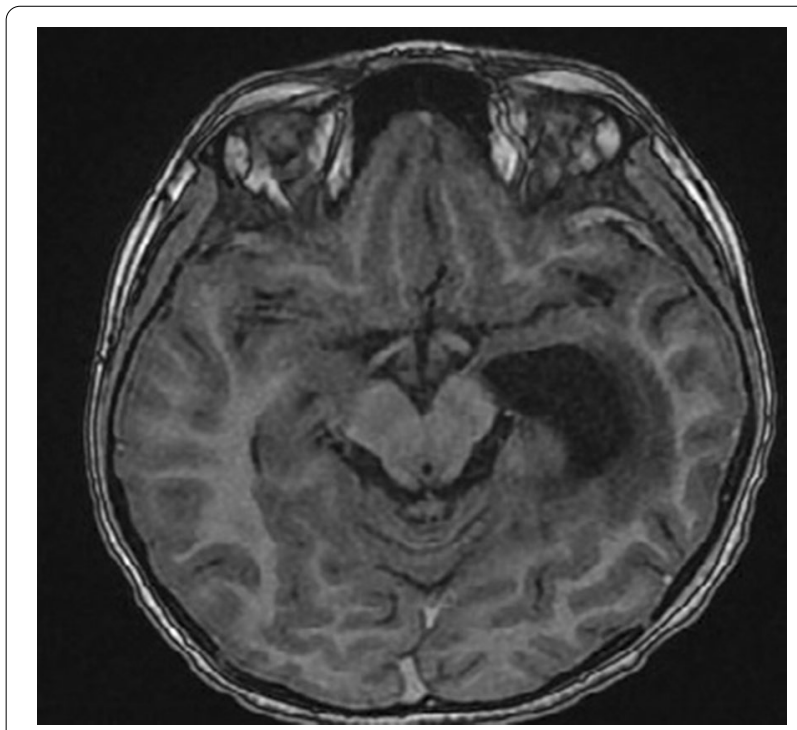

Fig. 3 Postsurgery T1WI showing a resection cavity in the left temporoparietal lobes with no signs of any residual neoplastic tissue
Surgery remains to be the cornerstone of management, and the completeness of resection influences patient survival. Achieving gross total resection (GTR) is the most decisive factor for a patient's long-term survival and prognosis. Various studies have determined that patients who have undergone GTR have significantly better survival rates [5, 6]. Furthermore, Mallick et al. [7] observed that progression-free survival was significantly higher for patients with GTR in comparison with subtotal resection (60 months versus 11 months) after eliminating the impact of adjuvant therapy. In addition, the extent of surgical resection remained a significant factor affecting survival [7]. Despite the merits of GTR, it is often difficult to achieve complete resection and it has increased morbidity. The large size, high vascularity, diffuse infiltrative nature, and excessive friability of $\mathrm{CPC}$ present a formidable challenge for complete resection. In the pediatric population, blood loss may be life threatening as the entire circulating blood volume may be lost during the resection of these vascular tumors. The surgical approach planned should allow good visual access to vascular supply and maximal exposure of the tumor mass. An effective intraoperative surgical strategy is to identify and ligate the feeding choroidal vessel, thus facilitating the en bloc tumor mass removal. In patients with large tumors where the tumor is resected in parts, gentle coagulation of the fronds of the tumor allows for manipulation without excessive bleeding and may reduce the tumor size. If complete resection is not achieved for any reason, a second-look surgery may achieve an eventual GTR, or this surgery may be preceded by administration of chemotherapy, which will to reduce intraoperative bleeding and tumor size, thus allowing for a complete subsequent resection rather than an incomplete resection [8-10]. In our patient, a successful GTR was performed via a transcortical approach.

A global consensus on neoadjuvant chemotherapy and regimens is lacking and is yet to be standardized. The following drugs are used in the treatment: carboplatin, etoposide, cyclophosphamide, high-dose methotrexate, and vinca alkaloids [11]. All meta-analyses have focused primarily on the benefits of using chemotherapy, without a focus on a particular regimen or agent. Using multivariate Cox regression survival analysis, Sun et al. [12] confirmed a better prognosis and a significantly better cumulative overall survival in children with CPC receiving chemotherapy alone. However, the implementation of combined chemoradiotherapy had better overall survival than chemotherapy alone [12]. Besides, among patients with incomplete resection of $\mathrm{CPC}$, chemotherapy was found to significantly improve the overall survival, but in the subgroup with complete resection, chemotherapy did not make an apparent difference [6]. Additional 
consideration of chemotherapy is given in children younger than 2 years for whom RT is preferably delayed [7]. Neoadjuvant chemotherapy has been recommended as it improves the margin of tumor resection with a decrease in the incidence of intraoperative blood loss in children [11]. The best chemotherapy regimen is yet to be determined, but a combination utilizing platinum and etoposide as backbone is preferred [7].

Radiation therapy (RT) is an important aspect of management, but its implementation is limited in young children $(<2$ years). Among a database of 524 patients, 5 -year survival was better in irradiated CPC patients [13]. A systematic review has also shown better 5-year overall survival among patients who received radiation therapy in comparison with those who did not receive RT (47.4 $\pm 6.5 \%$ versus $25.2 \pm 4.3 \%$ ) [6]. In another metaanalysis, Mazloom et al. [14] support the use of RT as it improved the progression-free survival as well as the overall survival [14]. In addition, they also established that patients receiving complete craniospinal irradiation had a significantly increased progression-free survival as well as overall survival than those who received limited RT treatment volumes such as whole-brain or involvedfield RT [14]. However, the decision of craniospinal irradiation will have to be made on a case-by-case basis after a complete MRI evaluation of the spine and examination of cerebrospinal fluid (CSF). Our patient has also received adjuvant $\mathrm{RT}$, as he belonged to a higher age group.

Despite CPC carrying a poor prognosis, our patient underwent a successful gross total resection (GTR) and received postoperative radiotherapy. He made a satisfactory recovery, with a further plan to review with gadolinium-enhanced neuroimaging at a later date.

\section{Conclusion}

We conclude that, when possible, GTR should be a priority in the management of patients with CPC. However, in the event of subtotal resection, neoadjuvant chemoradiotherapy may be given for a second surgery to achieve a complete GTR. Adjuvant radiotherapy and chemotherapy have been shown to improve survival in a recent meta-analysis. However, more studies need to be carried out for a global consensus.

\section{Acknowledgements}

Not applicable.

\section{Authors' contributions}

PZJ and PK were major contributors to writing this manuscript and patient care. AV and PZJ were responsible for the initial idea and revision of report. KV overlooked the patient's management and corrected the final manuscript. JV and SD critically reviewed and corrected the manuscript. All the authors have read and approved of the final manuscript.
Funding

Not applicable.

Availability of data and materials

The datasets used and/or analyzed during the current study are available from the corresponding author on reasonable request.

\section{Declarations}

\section{Ethics approval and consent to participate}

The authors certify that they have obtained all appropriate patient consent forms. In the form, the patient's parents have given their consent for the patient's images and other clinical information to be reported in the journal. The patient's parents understand that their names and initials will not be published, and due efforts will be made to conceal their identity, but anonymity cannot be guaranteed.

\section{Consent for publication}

Written informed consent was obtained from the patient's parents for publication of this case report and any accompanying images. A copy of the written consent is available for review by the Editor-in-Chief of this journal.

\section{Competing interests}

The authors declare that they have no competing interests

Received: 19 January 2021 Accepted: 18 March 2021

Published online: 21 April 2021

\section{References}

1. Ostrom QT, Gittleman H, Fulop J, Liu M, Blanda R, Kromer C, et al. CBTRUS statistical report: primary brain and central nervous system tumours diagnosed in the United States in 2008-2012. Neuro Oncol. 2015;17(Suppl 4):iv1-62.

2. Louis DN, Perry A, Reifenberger G, von Deimling A, Figarella-Branger D, Cavenee WK, et al. The 2016 World Health Organization classification of tumours of the central nervous system: a summary. Acta Neuropathol. 2016;131(6):803-20.

3. Gopal P, Parker JR, Debski R, Parker J. Choroid plexus carcinoma. Arch Pathol Lab Med. 2008;132(8):1350-4.

4. Lam S, Lin Y, Cherian J, Qadri U, Harris DA, Melkonian S, et al. Choroid plexus tumours in children: a population-based study. PNE. 2013:49(6):331-8.

5. Wolff JEA, Sajedi M, Brant R, Coppes MJ, Egeler RM. Choroid plexus tumours. Br J Cancer. 2002;87(10):1086-91.

6. Wrede B, Liu P, Wolff JEA. Chemotherapy improves the survival of patients with choroid plexus carcinoma: a meta-analysis of individual cases with choroid plexus tumours. J Neurooncol. 2007;85(3):345-51.

7. Mallick S, Benson R, Melgandi W, Rath GK. Effect of surgery, adjuvant therapy, and other prognostic factors on choroid plexus carcinoma: a systematic review and individual patient data analysis. Int J Radiat Oncol Biol Phys. 2017;99(5):1199-206.

8. Lafay-Cousin L, Mabbott DJ, Halliday W, Taylor MD, Tabori U, Kamaly-Asl ID, et al. Use of ifosfamide, carboplatin, and etoposide chemotherapy in choroid plexus carcinoma. J Neurosurg Pediatr. 2010;5(6):615-21.

9. Schneider C, Kamaly-Asl I, Ramaswamy V, Lafay-Cousin L, Kulkarni AV, Rutka JT, et al. Neoadjuvant chemotherapy reduces blood loss during the resection of pediatric choroid plexus carcinomas. J Neurosurg Pediatr. 2015;16(2):126-33.

10. Wrede B, Liu P, Ater J, Wolff JEA. Second surgery and the prognosis of choroid plexus carcinoma - results of a meta-analysis of individual cases. Anticancer Res. 2005;25(6C):4429-33.

11. Zaky W, Finlay JL. Pediatric choroid plexus carcinoma: biologically and clinically in need of new perspectives. Pediatr Blood Cancer. 2018;65(7):e27031.

12. Sun $M Z$, Ivan ME, Oh MC, Delance AR, Clark AJ, Safaee M, et al. Effects of adjuvant chemotherapy and radiation on overall survival in children with choroid plexus carcinoma. J Neurooncol. 2014;120(2):353-60. 
13. Wolff JE, Sajedi M, Coppes MJ, Anderson RA, Egeler RM. Radiation therapy and survival in choroid plexus carcinoma. Lancet. 1999;353(9170):2126.

14. Mazloom A, Wolff JE, Paulino AC. The impact of radiotherapy fields in the treatment of patients with choroid plexus carcinoma. Int J Radiat Oncol Biol Phys. 2010;78(1):79-84.

\section{Publisher's Note}

Springer Nature remains neutral with regard to jurisdictional claims in published maps and institutional affiliations.
Ready to submit your research? Choose BMC and benefit from:

- fast, convenient online submission

- thorough peer review by experienced researchers in your field

- rapid publication on acceptance

- support for research data, including large and complex data types

- gold Open Access which fosters wider collaboration and increased citations

- maximum visibility for your research: over 100M website views per year

At BMC, research is always in progress.

Learn more biomedcentral.com/submissions 